\title{
Research on Taijiquan Teaching Reform of Public Sports in Private Vocational Colleges from the Perspective of Teaching Environment
}

\author{
Lin Wang ${ }^{a}$, Weifeng Deng \\ Hainan Vocational University of Science and Technology Haikou, Hainan 571126, China \\ a249550389@qq.com, b893094362@qq.com,
}

Keywords: Public sports, Taijiquan, Vision of teaching environment

\begin{abstract}
College students, as an important force in China's social development, have attracted wide attention from all walks of life. How to promote the steady improvement of college students' physical quality has become the main problem faced by public physical education teachers in private vocational colleges in the teaching process. Taijiquan, as one of the national fitness sports, has become a compulsory content of college public physical education class. However, there are still some shortcomings in Taijiquan teaching in public physical education class, which affect students' interest in learning. Taijiquan is an important part of physical education in Colleges and universities in China, but it is difficult to arouse the enthusiasm and enthusiasm of modern students because of its boring performing routine learning and slow and stable movement rhythm. In order to enable college students to learn and practice Taijiquan in a limited time, private vocational colleges need to update teaching concepts and change teaching models based on the perspective of teaching environment, constantly reform and innovate teaching methods and training means, and explore a new teaching way.
\end{abstract}

\section{Introduction}

Taijiquan is an important representative item of traditional sports in China. It has a history of thousands of years in China. It is an important means for people to strengthen their bodies, entertain their bodies and minds, and prevent diseases. Taijiquan is a good way to promote my country's traditional sports culture [1]. Tai Chi as a popular fitness program for the whole people, is deeply loved by the people. As a traditional Chinese sports event with profound cultural background, Tai Chi has long been included in the compulsory content of public physical education by many private colleges and universities [2]. The country attaches great importance to Tai Chi, a traditional martial arts sport, and has included Tai Chi as a course in the teaching plans of colleges and universities. Through learning Tai Chi exercises, students exercise their bodies, promote healthy physical and mental development, and also help students establish correct life values [3]. At present, various colleges and universities across the country have opened Taijiquan programs, but some students feel that Taijiquan moves slowly and has little exercise value for themselves. Taijiquan is an important content of physical education in colleges and universities in our country, but due to its boring performance-style learning, coupled with the slow and steady rhythm of exercise, it is difficult to arouse the enthusiasm and enthusiasm of modern students in learning [4]. Due to the inadequate understanding of the cultural connotation, offense and defense of Taijiquan by college martial arts teachers, and the single teaching method, students do not understand the profound cultural background of Taijiquan, a traditional national sports [5].

As an important force in the development of our society, college students' physical fitness has attracted widespread attention from all walks of life. How to promote the steady improvement of college students' physical fitness has become the main problem faced by college public physical education teachers in the teaching process [6]. Due to the increase in the number of students in colleges and universities after the expansion of enrollment in recent years, the teaching hours of Taijiquan as a public physical education course are small, and the popularization of Wushu 
philosophy research results is not high, so that Taichiquan courses continue to expose problems in the teaching process [7]. Tai Chi is an important representative item of traditional sports in China. It has a history of thousands of years in China. It is an important means for people to strengthen their bodies, entertain their bodies and minds, and prevent diseases [8]. There are still some problems and shortcomings in teaching content, methods, and evaluation of Tai Chi teaching in colleges and universities [9]. In order to enable college students to learn and practice Taijiquan within a limited time, it is necessary to boldly update teaching concepts and change teaching models, continuously reform and innovate teaching methods and training methods, and explore a new way of teaching. Based on the analysis of existing problems, the article puts forward corresponding teaching reform ideas. So as to make full use of the advantages of the new physical education curriculum in teaching evaluation, improve the comprehensive quality of teachers and improve the comprehensive ability of students.

\section{Practical Problems Faced by Taijiquan Teaching in Private Vocational Colleges}

\subsection{Cognition stays on the surface}

Taijiquan combines fitness with profound culture, so it has become a compulsory course of public physical education in colleges and universities. China is an ancient country with a civilization history of 5,000 years. Excellent traditional culture has a profound influence on the formation and development of Taijiquan. The principles and methods of Taijiquan embody the traditional philosophy. The unique cultural tradition formed by the Chinese nation in the long history of development has had a profound impact on ancient and modern China. According to the theory of oriental medicine, exercise and breathing are harmonious when practicing Taijiquan. It can promote the circulation of qi and blood in the body, dredge channels and collaterals, and play a role in body building. In addition to educational background, personal ability and life experience, as well as other factors that choose the learning behavior of private vocational college students in Taiji, it can be said that these differences are caused by the similarity and difference of cardiopulmonary function changes. Understand the changes of heart and lung function of Taijiquan college students, identify the changes of heart and lung function, and use appropriate teaching methods and tools to motivate students not only to learn Taijiquan, but also to develop lifelong exercise habits. The effective attribution is that students can fail to learn Taijiquan due to unstable factors such as bad luck or lack of hard work. College students cannot receive professional Taijiquan knowledge and skills training, which not only increases the difficulty of learning Taijiquan, but also reduces the enthusiasm of students. Compared with its technical content, the cultural connotation of Taijiquan has richer inside information and vitality. Therefore, in Taijiquan teaching in colleges and universities, the cultural connotation of Taijiquan should be integrated into classroom teaching. Flexible organization and systematic planning are the essential points of Taijiquan teaching methods in colleges and universities, and individualized and diversified implementation is the soul of teaching methods. Many Taijiquan teachers are non-professional physical education teachers, and their own understanding of Taijiquan is not in place, which ultimately has a negative impact on students' understanding and feeling of Taijiquan [10]. When teaching, teachers should start from a comprehensive perspective, link theory with practice, and explain while practicing in class. Then the teacher puts forward some small questions for the students to think about and answer, and the students can also ask the teacher some questions or discuss some questions with the teacher. Only in this way can it meet the needs of contemporary college students' physical education class teaching.

Taijiquan not only has the effect of keeping fit, but also has profound connotation and rich cultural heritage. However, in Taijiquan teaching, teachers often only pay attention to the teaching of boxing routines, but neglect the explanation of its connotation, and even fail to explain the fitness mechanism and the function of preventing and treating diseases of Taijiquan. As a result, students do not have a complete impression of Taijiquan and can't realize the exercise value of Taijiquan. All the information that educators act on learners in educational activities includes not only the whole 
content of information, but also the form of information selection, transmission and feedback, which is the unity of form and content. It is necessary for colleges and universities to improve the teaching methods of Taijiquan. From the perspective of meeting students' needs, and on the basis of summing up the previous teaching experience, they try to construct a new teaching mode, and practice it in the teaching process and constantly improve it. Because most students don't have a certain martial arts foundation and have less teaching hours, it is easy for students to have the idea that Taijiquan is difficult to learn and remember. With this idea, students will not be strict with themselves in class.

\subsection{Lack of uniform standards}

The purpose of college students entering colleges and universities is for the smooth employment in the future, so the investment in basic and professional knowledge education is relatively large. Students' learning needs evaluation. Only proper evaluation can promote learning better, which is conducive to better teaching. Teaching evaluation is the value evaluation of teaching effect based on teaching objectives, which serves for teaching decision-making. It generally includes the evaluation of teachers, students, teaching content, teaching methods, teaching environment, teaching management and other factors in the teaching process. Any physical exercise must develop scientific methods, otherwise it will not be able to achieve the purpose of promoting human physical fitness. The emotional factors of Taijiquan among college students play an important role in all sports factors, and are the connection between various attitude problems of cognition and behavior. Emotion is a psychological reflection of cognition and plays a leading role in behavior. With the development of the school year, students' enthusiasm for their studies gradually weakens, and students' interest will focus on completing their studies instead of acquiring knowledge and skills of Taijiquan.The emotional factors of Taijiquan among college students play an important role in all sports factors, and are the connection between various attitude problems of cognition and behavior. Emotion is a psychological reflection of cognition and plays a leading role in behavior. With the development of the school year, students' enthusiasm for their studies gradually weakens, and students' interest will focus on completing their studies instead of acquiring knowledge and skills of Taijiquan.The assessment and evaluation of Taijiquan Teaching in public physical education in Colleges and universities should be the evaluation of students' sports skills, learning attitude and behavior norms, communication and cooperation spirit, and it is also an evaluation of the effect and process of learning Taijiquan.

In general, most colleges and universities in the process of setting up physical education courses, are set according to the standard once a week. This requires students to make full use of their spare time to strengthen exercise in order to achieve the purpose of promoting their own physical fitness. The spread of Taijiquan is a national sports culture. In the market economy, the marketization and socialization of Taijiquan and its culture is an inevitable development trend. In the process of spreading Taijiquan, people often pay attention to technical communication but neglect cultural communication, and the cultural connotation of Taijiquan is the core of its rich heritage and vitality. There is no unified evaluation standard for Taijiquan Teaching of Public Physical Education in most colleges and universities. Even in the same university, different physical education teachers have different evaluation standards for Taijiquan learning, which is unfavorable to Taijiquan teaching. In addition to learning Taijiquan knowledge in class, most students seldom practice Taijiquan knowledge and technology in their spare time, which has a negative impact on the improvement of Taijiquan teaching efficiency.

\section{Thoughts on Taijiquan Teaching Reform in Private Vocational Colleges}

With the rapid development of science and technology, more and more modern technology has entered the university classroom teaching. In the teaching process, teachers combine modern multimedia teaching technology with Taijiquan teaching closely, which not only promotes the continuous improvement of students' enthusiasm for learning Taijiquan, but also promotes the application of multimedia teaching methods. College students are interested in fighting sports 
because they think fighting sports are practical and students are willing to learn useful knowledge or skills. Teachers explain the offensive and defensive meanings of Taijiquan in concise language when demonstrating movements, which makes it easy for students to understand the practicality and fitness of Taijiquan, which obviously will greatly enhance students' awareness and interest in learning Taijiquan. Teachers must give full play to the positive role of traditional campus media and new media in the process of Taijiquan teaching, and attract experienced Taijiquan teachers to actively participate in the teaching process of Taijiquan [11]. In order to complete the teaching content effectively, teachers must use the integrated teaching method and the decomposed teaching method in Taijiquan teaching. In teaching, it is generally necessary to demonstrate the complete actions first, and then divide the complete actions into separate actions for teaching. In the teaching activities, we should first demonstrate the complete actions, and then demonstrate the decomposed actions, especially for the difficult actions. The purpose of decomposition teaching is to reduce the difficulty of complex movements and finally complete the whole set of movements teaching.

By reasonably organizing the content of preparation activities and reasonably connecting general warm-up exercises with special warm-up exercises, you will be able to carry out preparation activities similar to the special skill requirements of Taijiquan and prevent sports injuries in the special training of Taijiquan. The structure of Taijiquan to prevent special sports injuries is shown in Figure 1.

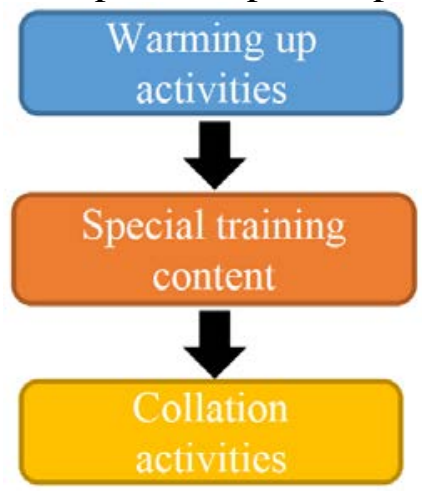

Figure 1 The system structure of Taijiquan special subject injury prevention method

Colleges and universities must combine the associations organized by students spontaneously with the development of Taijiquan, and hire professional Taijiquan teachers to guide students according to the requirements of Taijiquan, which not only helps the members of the associations to deepen their understanding and grasp of the essentials of Taijiquan, but also promotes the effective management efficiency of college students' associations. In the teaching practice of Taijiquan, the teaching contents of basic movements and posture are secondary. It is important to explain the connotation of traditional culture carried by Taijiquan to students through these techniques, so that students can not only recognize the differences and advantages between Taijiquan and western sports in health care.

After long-term training in Taijiquan, the heart rate of the subjects decreased. To a large extent, it is due to the increase of myocardial contractile force, the change of sympathetic and vagus nerve tension stimulates the heart, and the healthy Qigong of various parts of the human body needs to promote most of the blood circulation of the human body. Figure 2 shows the structure of cardiopulmonary function control.

In the process of Taijiquan activities, different learning methods must be formulated according to students with different constitutions, so that students can gradually like Taijiquan. In order to improve efficiency, modern means such as TV, video and multimedia music can be used to increase the visual image of teaching content, arouse and improve students' enthusiasm for learning, and thus improve students' thirst for knowledge [12]. Students are divided into groups and recorded by the group leader and the sports committee every day. Teachers communicate with students from time to time to inform them of their appreciation of extracurricular activities and deep understanding of Taiji culture, and further spread the intangible culture of Taiji in university education. In teaching evaluation, a comprehensive evaluation method combining quantitative and qualitative methods should be adopted, that is, students' mutual evaluation and teachers' mutual evaluation should be 
emphasized. First, PE teachers should set an example, set up new evaluation ideas in time, think about more reasonable evaluation methods, and build a diversified teaching evaluation system. This is conducive to enhancing students' interest in learning Taijiquan, improving students' comprehensive ability and teaching effect. In the process of teaching, teachers must correct students' common mistakes when correcting mistakes, and teachers must think carefully when correcting mistakes, so as to enable students to correctly understand and master them.

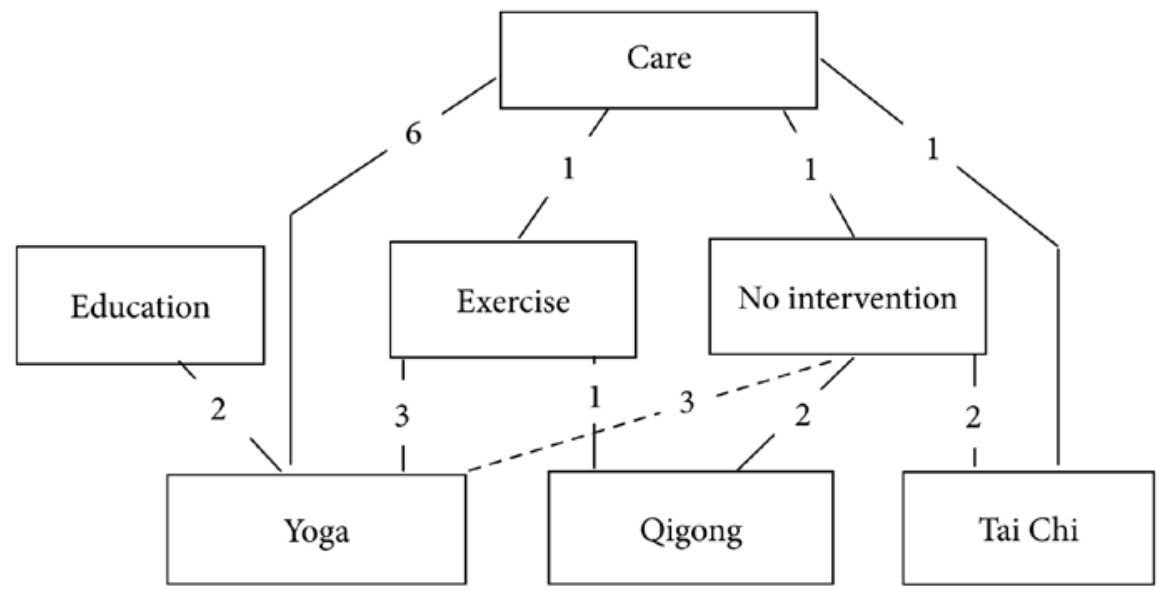

Figure 2 The structure of cardiopulmonary function control

\section{Conclusions}

At present, the development of Taijiquan in public physical education class in colleges and universities in China is not smooth. Although most colleges and universities offer Taijiquan teaching, students do not like Taijiquan teaching, teachers' poor level, backward teaching methods and outdated teaching contents are the reasons that affect Taijiquan teaching. Taijiquan teaching in colleges and universities should not be limited to the traditional teaching methods. Taijiquan teachers in colleges and universities should give full play to their personal abilities and think of new teaching methods and forms that keep pace with the times to enrich Taijiquan teaching in colleges and universities. As a higher educator standing at the commanding height of education, we should do a good job in Taijiquan teaching, and have the responsibility to supplement the related techniques and techniques to the teaching, and constantly enrich and improve all aspects of teaching. In teaching activities, we should first demonstrate the complete actions, and then demonstrate the decomposed actions, especially for the difficult actions. First of all, PE teachers should set an example, set up a new evaluation concept in time, think about more reasonable evaluation methods, and build a diversified teaching evaluation system, which is conducive to improving students' interest in learning Taijiquan and improving students' comprehensive ability and teaching effect.

\section{Acknowledgements}

[Foundation project] 2019 Hainan Provincial Higher Education Scientific Research Project (HnKy2019-104)

\section{References}

[1] Yu Zhouqun. Thoughts on the effect of Taijiquan teaching in college physical education[J]. Youth, 2019, 000(027):177, 212.

[2] Lu Weishang, Wang Changlong. Research on University Participation in Government Purchase of Public Sports Services [J]. Journal of Fuqing Branch of Fujian Normal University, 2019, 000(002): 100-104. 
[3] Cui Weijuan. Research on the promotion measures of Taijiquan courses based on public sports in colleges and universities [J]. Stationery \& Sports Articles \& Technology, 2019(3):131-132.

[4] Xu Jiangjuan. Research on the Status Quo and Countermeasures of Taijiquan Teaching in Public Physical Education in Colleges and Universities [J]. Stationery \& Sports Articles \& Technology, 2019, 000(021):129-130.

[5] Chen Langbo. The means and methods of cultivating students' interest in Taijiquan in physical education classes of higher vocational colleges [J]. Contemporary Sports Science and Technology, 2019, 9(01):116-117.

[6] Liu Yuan. Research on the Current Situation and Countermeasures of Taijiquan Teaching in Public Physical Education in Nanjing Colleges and Universities [J]. Chinese Nationalities Expo, 2017, 000(008): 90-91.

[7] Chen Jie, Gu Feifei. Probe into the introduction of Taijiquan teaching into college public physical education [J]. Education Modernization, 2017(22):133-134+138.

[8] Song Qinghua. Research on the promotion measures of public sports Taijiquan courses in ordinary colleges and universities [J]. Hubei Sports Science and Technology, 2015, 000(001):63-66.

[9] Liu Bo. Teaching Research on Tai Chi Sports Elective Course in Higher Vocational Colleges [J]. Sports Fashion, 2017, 000(008): 63-64.

[10] Dong Shibiao. Research on the feasibility of Tai Chi's entry into physical education in colleges and universities [J]. Sports Culture Guide, 2015, 000(007): 14-17.

[11] Liu Baihui. Taking Taijiquan as an example to analyze the status quo of college physical education [J]. Urban Family Education Monthly, 2016, 000(012):281-282.

[12] Lv Yunlong. Exploration of Taijiquan in public physical education class[J]. Sports, 2016, 131(03):119-120. 